Although Vichy pronounced women's role to be in the home, Clark concludes that its policies increased women's awareness of public issues, furthered their politicization, and thus led to a greater role for women in public administration in the post-war period. Nevertheless, this reader would conclude that over the last half of the twentieth century gender attitudes changed less rapidly in France than in much of the West. Although one would need more comparative statistics to be certain, French women seem now to play a lesser role in government service than they do in many Western countries. They always held a small percentage of posts.

The Rise of Professional Women is a well-researched, sensitive, and incisive study. It is important for those interested in themes of education, gender, and professionalization. It offers a comparative framework, statistics, and case studies. One wonders however why the author did not include a chapter of conclusions.

Patrick J. Harrigan

University of Waterloo

\title{
Angela Ward and Rita Bouvier, eds. Resting on Mother Earth: The Aboriginal Experience in Urban Education Settings. Calgary: Detselig Enterprises, 2001.
}

This book is a thoughtful and collaborative work by two educators who have produced a focused view, as well as a heartfelt and instructive anthology, on the education of urban Aboriginal students. The book explores the possibilities under which Aboriginal people might have a sense of cultural identity and belonging while living in and becoming educated in an urban environment removed from family members and other cultural influences. Their problems are exacerbated by social stratifications which are, at best, indifferent and, at worst, openly racist towards indigenous peoples. The book explores social, relational, and educational conditions which confound and also those which support students of all ages in identity-affirming work.

The question the book answers is how we might think about the education and identity formation of Aboriginal students in urban settings. Although this question of identity is not peculiar to urban settings, it brings to the fore the tension around the general 
application of Aboriginal culture as a curative to social, economic, and educational problems that Aboriginal people face. The authors recognize that oppressions on the basis of race, class, and gender seriously reduce one's life chances. They also acknowledge that belonging to a supportive community improves one's possibilities for positive identification and wholeness in all aspects of life. But what is the role of culture for urban Aboriginals? Is culture always positive and always a cure? Is culture so deep-rooted, and so fundamental a part of Aboriginal character that one would not be Aboriginal without it? The question of cultural as a condition of authenticity fuels a long-standing debate about how "Indianness" is constituted. The issue is especially pertinent to the lives of urban people who have been away from traditions and family for generations. Through the selection of some of the pieces for the anthology, editors Bouvier and Ward would seem to answer the question about the determinism of culture in the affirmative. The answer is qualified, however, for in her chapter Bouvier defines "authenticity" as follows: "Authenticity as a foundation in relationships should reflect the quality of our being, rather than just the position or role we might hold” (p. 57). The editors have attempted to avoid a kind of essentialism with respect to culture, and in most chapters they succeed. They have also offered a fine collection of pieces which describe the problems and some of the solutions that may be found in the education of urban Aboriginal people.

The book is framed by the introduction and the closing words of the editors (who are also authors) in the form of a reflective conversation. In between are four themes that describe various aspects of education in urban areas. In spite of the explanatory logic served by these themes, the chapters have an even more compelling point of connection. In some way or other, every chapter engages in an aspect of story-telling. Some are narratives; others are research accounts; and some are narratives about research and teaching. All the chapters have aspects of the personal and all are instructive. The narratives are perhaps the most powerful because of the almost irresistible quality of the personal stories which speak directly to the listener/reader.

Shauneen Pete-Willett writes a narrative essay on her experiences as a consultant for Indian and Metis Education. Her role began by "doing” workshops which consisted, in part, of storytelling and crafts. Some teachers imagined that only an Aboriginal person could teach the kinds of things she was offering and expected her to return yearly to perform the events. Also, crafts 
came to symbolize all there was to know about Aboriginal culture. By mentoring teachers and modelling what they could do, PeteWillett encouraged them to take responsibility for providing integrative and inclusive education for their own classes. The narrative by Lon Borgerson and twenty-three pre-service teachers from the Saskatchewan Urban Native Teacher Education Program (SUNTEP) is perhaps the most compelling. The chapter describes some of the history of the SUNTEP theatre and the unfolding performance of the title play, "Voices Given to Us." Through the collective aspect of script development, rehearsals, and performance, community identity grows among the students. The account-in which students tell stories about people who have been important in their lives - is a very moving chapter. SUNTEP theatre demonstrates the courage that Aboriginal students display in claiming their education. The chapter is an important reminder that positive learning experiences can and do go on in the midst of urban life as long as there are supportive teachers who care about and advocate for Aboriginal students. The remaining narrative chapter by Dottie King and Bill Walters consists of the personal accounts of Aboriginal people who have benefited from education and jobs to be found in urban settings. Even after many years, they still long to return to their traditional communities to reconnect with values that have been important to them. In the excerpts from their lives, all of the people declare their intentions to return to the land they once knew. Knowing that a "homeland" or home place exists seems important in the understanding of themselves as Aboriginal people.

The book features several research studies conducted among urban youth. Carol Reid makes the case that while pathologizing a culture has become a thing of the past as an explanation for educational failure, the current trend in Aboriginal education toward the promotion of self-esteem is still problematic. Because one's identity does not exist outside of culture, the selfdetermination promoted by a self-esteem approach is an inadequate solution. Rather, Reid suggests that the answer to individual problems lies in community self-determination and community context. Heather Blair offers a critical analysis of how Aboriginal school girls are marginalized through complex discourses of gender, race, ethnicity, and class. She shows how their identities are produced through the social contexts and by their own participation in or resistance to normative practices. Blair concludes that marginality may be chosen by some Aboriginal girls as a way to avoid the worst of social interaction with both girls and 
boys in their peer group. The chapter by Linda Wason-Ellam reminds us that telling our stories and listening to those of others is central to the achievement of mutual acceptance. She says: "When children converse, these everyday impromptu stories or 'memory moments' enabled them to legitimize their sense of self as they attempted to make meaning of the experiences, beliefs and values of their own culture” (pp. 96-7).

Carol Leroy describes the importance of teacher acceptance of vulnerable students. A teacher in the study "mis-reads" a blondhaired, blue-eyed child as having fewer identity needs even though the child's mixed-race ancestry is a source of great confusion for the student. Although Leroy does not specifically say this, one can see how important it is that teachers demonstrate a strong antiracist stand and an active acceptance of Aboriginal students if they are to claim a positive identity.

All of the authors exhibit passion for their topics, but perhaps none more so than Bente Huntley in her description of integrative science education in a pre-service program. Following an integrative program means paying attention to the participation of female students as well as teaching them to respect the environment in a way that is also paralleled by traditional First Nations. Enthusiasm for her topic is evident in the suggestions for how teachers and students can be engaged in the excitement of science. Angela Ward writes a reflective chapter based on her intellectual and inter-cultural journeys over the course of her research career in Canada. Teaching school in small communities and now in a teacher education program, she has focused on language as a key to supporting her students. She bravely reports how, at first, she mistakenly thought that it was Aboriginal children's "language difficulties" that kept them from succeeding. She now concludes that the lack of respect shown to Aboriginal students and their needs is an effect of power imbalances and colonizing practices.

To conclude, Rita Bouvier's chapter on community schools is very strong. She argues that liberal forms of education for and about Aboriginal students which promote merely tolerance and appreciation are no longer acceptable. Instead she speaks of activism, politics, power, and the observation that education is not a neutral encounter. Rather, as she and the other contributors have shown, urban education is a struggle that must be actively engaged. The fight is over equitable social relations for Aboriginal children in urban settings. Nothing less will do.

How to support the cultural and identity needs of urban youth is a paramount question throughout education jurisdictions 
anywhere. The strong narrative voices throughout this book offer many brave challenges and some shining examples. None of it looks easy. Perhaps the best example is provided by Bouvier and Ward as they collaborate across the Aboriginal/non-Aboriginal divide of personal location. They have named their differences in ways that account for their contrasting strengths, weaknesses, and insights. This book makes a contribution to cross-cultural studies in urban contexts when it reminds us that teachers' positive recognition of students' Aboriginal heritage and ancestry enables students to connect in life-affirming ways with their culture.

Carol Schick

University of Regina

John S. Milloy. “A National Crime": The Canadian Government and the Residential School System, 1879 to 1986. Winnipeg: University of Manitoba Press, 1999. Pp. 402. Illus.

"A National Crime" examines the relationship between, as its subtitle indicates, "the Canadian Government and the Residential System, 1879 to 1986," by which time residential education for Aboriginal children was largely a thing of the past. Drawing on primary research undertaken for the 1996 Royal Commission on Aboriginal Peoples, John Milloy offers a detailed narrative divided into three parts. The first examines the origins of government policy, the second various aspects of residential school life through the Second World War, and the third the system's decline. Chapter 3 , detailing the "vision" behind residential schools, and chapters 9 and 10, on school closures, are especially valuable for setting out government policy during two critical time periods. Milloy's efforts to disentangle schools' funding arrangements are similarly commendable.

The book's title, “A National Crime," gives it a particularly engaging quality. It also raises a very important larger question. What precisely was the crime? Was it the schools themselves, their very existence, or rather that they were not as effective as they might have been? It may be more the latter, from Milloy's perspective, for the book's title is taken from a 1922 report 